\title{
FINITISM, DIVISIBILITY, AND THE BEGINNING OF THE UNIVERSE: REPLIES TO LOKE AND DUMSDAY
}

\author{
Stephen Puryear \\ North Carolina State University
}

Some philosophers contend that the past must be finite in duration, because otherwise reaching the present would have involved the sequential occurrence of an actual infinity of events, which they regard as impossible. I recently developed a new objection to this finitist argument, to which Andrew Ter Ern Loke and Travis Dumsday have replied. Here I respond to the three main points raised in their replies.

Keywords: Space, time, continuity, infinity, creation

\section{Introduction}

Some philosophers argue that the universe must have had a beginning, because otherwise reaching the present would have required something impossible, namely, the occurrence or 'traversal' of an actually infinite sequence of events. But this argument faces the objection that actual infinities are traversed all the time: for example, whenever a finite period of time elapses [Morriston 2002: 162; Sinnott-Armstrong 2004: 42-3]. Let us call these the finitist argument and the Zeno objection. In response to the Zeno objection, the most ardent proponent of the finitist argument in our day, William Lane Craig [Craig and Sinclair 2009: 112-13, 119; cf. Craig and Smith 1993: 27-30], has taken the position that 'time is logically prior to the divisions we make within it'. On this view, time divides into parts only in so far as we divide it, and thus divides into only a finite number of parts. As I [Puryear 2014] have argued, however, this reply raises a difficulty. For it seems to imply that past time, and thus past change, also divide into parts only in so far as we divide them, hence also divide into only a finite number of parts. From this perspective, an eternal past would not involve an actually infinite sequence of events after all. 
Finitism, Divisibility, and the Beginning of the Universe

Craig's reply to the Zeno objection would thus subvert the very argument it was intended to save.

My argument has elicited replies from Andrew Ter Ern Loke [2016] and Travis Dumsday [2016]. Here I address the three basic objections to emerge from those replies. The first two, due to Dumsday, concern the distinction between infinite magnitudes and infinite multitudes, and the distinction between extensively and intensively infinite progressions. The third objection, which both Loke and Dumsday urge in one form or another, concerns the possibility that time might be continuous yet naturally divide into smallest parts of finite duration.

\section{Infinite Magnitudes vs. Infinite Multitudes}

A key claim of my argument is that, if time divides into parts only in so far as we divide it, then reaching the present in a universe without beginning would not require traversing an actually infinite multitude of intervals or events. 'At most it would require traversing an infinite magnitude, something to which finitists have typically raised no objection' [Puryear 2014: 628]. To this Dumsday objects that traversals of infinite magnitudes are not clearly any less problematic than traversals of infinite multitudes [2016: 3]:

[I]t is counterintuitive to suggest that those worried about the possibility of traversing an infinite multitude would have no plausible corresponding concerns regarding the possibility of traversing an infinite magnitude.... [I]f one thinks it impossible to cross an infinitely large lake (for instance), it is not immediately clear why that intuition would be overthrown by being told that the lake has no real proper parts, being instead a single extended simple. For if the lake is a single infinite extended simple, it still seems prima facie impossible to swim across it. 
The main problem with this objection is that misgivings about infinite traversals - particularly those with an end but no beginning - have consistently been rooted in arguments concerning infinite multitudes, namely, of rooms, books, orbits, days, numbers, and so forth. This is no accident. The arguments all proceed by generating some alleged absurdity from the idea that one infinite multitude can be put in one-one correspondence with another. Craig [Craig and Smith 1993: 33-34; Craig and Sinclair 2009: 120-22], for instance, appeals to examples in which infinitely many past days stand in one-one correspondence with the negative integers, and again with the days recorded in an inverse Tristram Shandy diary. The principle that such multitudes are equal in size plays an essential role in the arguments (cf. Craig and Smith [1993: 23]). Yet for that very reason these arguments lose their teeth when we shift from infinite multitudes to simple infinite magnitudes, for which there is no analogous principle of correspondence. If beginningless traversals of such magnitudes are impossible, then the finitist owes us more of an argument for that conclusion than we have been given thus far.

As for Dumsday's lake example, if the body of water is supposed to be infinitely large in the sense that it extends without end in both directions, then I grant that one cannot possibly swim across it, regardless of whether it has an actual infinity of parts or not. But suppose instead that the person has been swimming forever and merely reaches a certain point in the lake. (Alternatively, suppose the lake is infinite only in the direction opposite the direction of the swimming, and that the person, having been swimming forever, reaches shore.) Unlike the case of swimming across a lake that is infinite in both directions, it is far from clear that this sort of beginningless progression is impossible. Indeed the only substantive arguments we have been given for the impossibility of such progressions depend essentially on the assumption of an 
infinite multitude of distinct steps, and thus have no obvious bearing on simple infinite magnitudes.

\section{Extensively vs. Intensively Infinite Progressions}

Dumsday also challenges the relevance of the Zeno objection to the argument for temporal finitism. As I have said, the Zeno objection purports to undermine the finitist rejection of infinite progressions by noting that such progressions take place all the time. According to Dumsday, however, it is not at all clear that these are the same kind of infinite progression. The Zeno case involves an extensively finite but intensively infinite progression: for instance, a finite period of time with an actual infinity of parts. In contrast, the argument for temporal finitism requires only the rejection of extensively infinite progressions that have an end but no beginning. Since progressions of the latter sort may raise an additional difficulty by dint of the lack of a starting point, Dumsday [2016: 4] concludes, 'It is not obvious that these two cases of traversing an infinite are sufficiently close, such that it would be obviously irrational to affirm the possibility of one while denying the possibility of the other'.

My reply to this is simple. If beginningless (and thus extensively infinite) progressions face a special difficulty in virtue of their lack of a starting point, which does not beset the extensively finite but intensively infinite Zeno progressions, then this needs to be shown. As it stands, the finitist argument I have criticized does not even purport to do this. It simply denies the possibility of forming an actual infinite by successive addition, without regard to whether the infinite thus formed is extensively or intensively infinite. Hence, if there is some special difficulty in the idea of a beginningless progression, then some further argument is needed to 
establish this; and it falls to the finitist who sees a relevant difference here to supply this argument.

\section{A Tertium Quid?}

I previously characterized Craig's suggestion that we divide time into parts, which he construes on conceptualist lines, as one of two basic replies available to the finitist (see Puryear [2014: 622]). ${ }^{1}$ The other rests on the view that time and thus change are discrete, which I set to one side. According to both Loke [2016: 2-4] and Dumsday [2016: 4-5], however, I have overlooked a third possibility. On this view, time is continuous and hence infinitely divisible, but is not actually divided to infinity. Rather, time naturally divides into smallest actual parts of finite duration, with any further divisions being only potential or conceptual. On such a view, events of finite duration never resolve into more than a finite number of actual temporal parts, thus never involve the sequential occurrence of an actual infinity of subevents. But reaching the present in a universe without beginning would involve such an occurrence. So the Zeno objection falls away, without imperilling the finitist argument or abandoning the continuity of time.

Obviously this reply cuts ice only if the proposed view is coherent. But I think we may reasonably doubt whether it is. For the view that time divides into 'distinct periods that exist apart from our conceptual activity’ [Loke 2016: 2], or into ‘objectively real actual parts' [Dumsday 2016: 4], seems to entail that time is discrete, not continuous. ${ }^{2}$ To see why, suppose

\footnotetext{
${ }^{1}$ Since Craig does not specify whether the divisions we make in time exist in reality or merely in thought, it would perhaps be better to describe his view as a form of conventionalism. For the purposes of this reply, however, I will stick with the conceptualist label. Nothing here hinges on the difference.

${ }^{2}$ Dumsday does not explain how space and time come to be actually divided. On the one hand, he [2016: 5] claims that 'the space in between A and B is merely potentially divisible, not actually already split up into real parts', which implies that something has to happen for space to divide into real parts. On the other hand, he denies that 'the divisions between A and B are based
} 
we have a period of time that begins at $t_{a}$ and ends at $t_{d}$, that is, $t_{a}-t_{d}$, and let us stipulate that this period of time naturally divides into two parts, $t_{a}-t_{b}$ and $t_{c}-t_{d}$. (Let us further assume that $t_{a}, t_{b}, t_{c}$, and $t_{d}$ are instants, not periods of time, since otherwise time would seem to be discrete.) Now here there seem to be three possibilities for understanding the relation of $t_{b}$ to $t_{c}$ : (i) $t_{b}=t_{c}$; (ii) $t_{b}$ is earlier than $t_{c}$, with no gap in between, that is, $t_{b}$ is before but 'next to' $t_{c}$; (iii) $t_{b}$ is earlier than $t_{c}$, with a gap in between. ${ }^{3}$ But options (ii) and (iii) both seem to imply that time is discrete. So, if time is to be continuous, that leaves us with option (i), on which the instant at which the first part of $t_{a}-t_{d}$ ends is the same instant at which the second part begins. Yet, if the instant at which $t_{a}-t_{b}$ ends is the instant at which $t_{c}-t_{d}$ begins, then what makes these really distinct parts of the period $t_{a}-t_{d}$, as opposed to parts that we merely conceive in that period? It would seem that an objectively real division would result in non-overlapping parts. But how could time divide into non-overlapping parts and yet still be continuous?

In his reply, Loke [2016: 4] claims that time can have distinct parts and still be continuous, as long as these parts are 'joined together'. He then illustrates the idea of joining together in the following way [ibid.]:

To illustrate one possible way of joining temporal parts, consider Aristotle's view that things neither move nor rest at a point, but instead move or rest only during an interval (Physics 232a32-4). The extensionless 'point of transition', which we conceptualise between 'moving interval' and 'resting interval', can be understood as the coincidence of the boundaries of the two intervals at which they join together; and, as Aristotle explained, there is neither motion nor rest at this (or any) point.

on nothing more than our conceptualization'. So the space between A and B comes to be really divided, but not through our conceptualization, or at least not through that alone. What exactly does effect the division remains unclear.

${ }^{3}$ These options correspond respectively to what Aristotle [Physics, V.3, 226b33-227a33] calls the continuous, the (merely) contiguous, and the (merely) successive. 
The thought here appears to be that the two intervals join together in virtue of the coincidence of their boundaries at an instant. In other words, the moving interval ends at the same instant the resting interval begins, as on option (i). However, Loke also describes this 'point of transition' as something we conceptualise, which seems to imply that, apart from our conception, there is no point of intersection, no coinciding boundaries, and thus no division. The implication appears to be that the moving and resting intervals are in reality just one interval that we divide in thought, whereas they were supposed to be really distinct. Indeed, Aristotle himself seems to hold that any such transition point could be only a potential division in time, since on his view actual divisions introduce discontinuities [Physics, VIII.8, 263a23-30] and time is continuous [Physics, V.2, 232b22-25]. Whether time could be both continuous and really divided into parts therefore remains to be seen.

One possibility I may seem to have overlooked is that each real division in time results in a closed boundary adjoining an open one (cf. Varzi [1997]). So, for example, if the closed temporal interval $\left[t_{1}, t_{3}\right]$ were bisected, the resulting parts would be either $\left[t_{1}, t_{2}\right)$ and $\left[t_{2}, t_{3}\right]$, or $\left[t_{1}, t_{2}\right]$ and $\left(t_{2}, t_{3}\right]$. An initial concern about this proposal is that it violates the Principle of Sufficient Reason, since there seems to be no principled reason why the interval would divide in one of these ways rather than the other [ibid.: 44]. But even worse, the idea that temporal intervals have open boundaries is itself doubtfully coherent, at least on an A-theory of time (cf. Dumsday [2016: 5-6]). Consider the interval $\left[t_{1}, t_{2}\right)$. By stipulation, it has no end, since any time we might specify within it will be followed by later times in the interval. Yet it must end before $\left[t_{2}, t_{3}\right]$ can begin. So an endless interval must somehow end. For the sceptic of infinite traversals, this would seem to be especially problematic. Again, consider the interval $\left(t_{2}, t_{3}\right]$. By stipulation, it has no beginning, since any time we might specify within it will be preceded by earlier times 
in the interval. Yet it evidently begins, since at $t_{2}$ it is not yet occurring, while after $t_{2}$ it is occurring. So a beginningless interval must somehow begin. This too seems problematic, especially for the finitist who insists that time itself could not fail to have a beginning.

Aside from these worries about coherence, there remains a further problem. Assume for the sake of argument that these doubts about coherence can be answered. If the goal were merely to show that time could be continuous and have smallest parts of some finite duration, or in other words, to show that the argument for temporal finitism is compatible with the continuity of time, then perhaps Loke and Dumsday would have succeeded. But this still does not fully vindicate the finitist argument. For as long as the conceptualist (or conventionalist) approach suggested by Craig's remarks also remains a viable option, then the finitist has not yet established the crucial premise that a beginningless past would consist in an infinite sequence of events (rather than one simple event that we divide in thought). In other words, in order for the finitist argument to go through without falling prey to the Zeno objection, the finitist needs time to have smallest natural parts. But if all that has been shown is that time could have smallest natural parts, not that it does have such parts, then temporal finitism has not been established. In order to fully vindicate the finitist argument, then, Loke and Dumsday not only need to say more in support of the coherence (and indeed the plausibility) of their alternative conceptions of time; they also need to show that the conceptualist alternative is not plausible, or at least that it is comparatively implausible. Until that has been done, the case for the finitist argument remains at best incomplete. 
Finitism, Divisibility, and the Beginning of the Universe

\section{Conclusion}

While Loke and Dumsday have certainly advanced the discussion, much work still needs to be done if the argument for temporal finitism is to be fully vindicated. The ball is still in the finitists' court. ${ }^{4}$

\section{References}

Craig, William Lane and Quentin Smith 1993. Theism, Atheism and Big Bang Cosmology, Oxford: Clarendon Press.

Craig, William Lane and James D. Sinclair 2009. The Kalam Cosmological Argument, in The Blackwell Companion to Natural Theology, ed. William Lane Craig and J. P. Moreland, Oxford: Wiley-Blackwell: 101-201.

Dumsday, Travis 2016. Finitism and Divisibility: A Reply to Puryear, Australasian Journal of Philosophy.

Loke, Andrew Ter Ern 2016. On Finitism and the Beginning of the Universe: A Reply to Stephen Puryear, Australasian Journal of Philosophy.

Morriston, Wes 2002. Craig on the Actual Infinite, Religious Studies 38/2: 147-66.

Puryear, Stephen 2014. Finitism and the Beginning of the Universe, Australasian Journal of Philosophy 92/4: 619-29.

Sinnott-Armstrong, Walter 2004. There Is No Good Reason to Believe in God, in God? A Debate between a Christian and an Atheist, ed. William Lane Craig and Walter SinnottArmstrong, Oxford: Oxford University Press: 31-52.

Varzi, Achille C. 1997. Boundaries, Continuity, and Contact, Noûs 31/1: 26-58.

\footnotetext{
${ }^{4}$ My thanks to Stephen Hetherington and two anonymous referees for helpful comments on a previous draft of this rejoinder.
} 